Investigaciones Fenomenológicas, vol. Monográfico 4/I (2013): Razón y vida, 119-132. e-ISSN: $1885-1088$

\title{
Some Phenomenological and Metaphysical Aspects of Human Creativity
}

\section{ALgUNOS ASPECTOS FENOMENOLÓgICOS Y METAFÍSICOS \\ DE LA CREATIVIDAD HUMANA}

\author{
Mamuka Dolidze \\ President of the Phenomenological Society of Georgia, \\ Institute of Philosophy, Georgia \\ mamuka dolidze48@yahoo.com
}

\begin{abstract}
The author gets human creativity to bridge phenomenology and metaphysics. He examines closely the poetical principle of Edgar Allan Poe and considers the artwork (poem) as a phenomenon appealing to the metaphysical beauty. He also considers the problem of freedom in phenomenological and metaphysical aspects of creativity. To harmonize the freedom and phenomenology the author offers to differentiate two kinds of intentionality: "intentionality to" and "intentionality from". The first is reducible to the purposefulness of events and refers to the constitutive function of consciousness, the latter implies the human creativity and freedom as an act of differentiation of phenomenon from its previous limits. The incipient point of the second form of intentionality seems to be a metaphysical object, which is worth considering as an inexhaustible source of the world of phenomena.
\end{abstract}

Key Words: Phenomenology, Metaphysics, Intentionality, Human Creativity.

\begin{abstract}
Resumen: El autor considera la creatividad humana pare tender un puente entre fenomenología y metafísica. Examina de cerca el principio poético de Edgar Allan Poe y considera la obra de arte (el poema) como un fenómeno que apela a la belleza metafísica. Considera el problema de la libertad en relación a los aspectos fenomenológicos y metafísicos de la creatividad. Para armonizar la libertad y la fenomenología, el autor propone diferenciar dos tipos de intencionalidad: "intencionalidad a" y "intencionalidad de (desde)". La primera es reducible a la intencionalidad (purposefulness) de los hechos y se refiere a la función constitutiva de la conciencia; la segunda implica la creatividad humana y la libertad como un acto de diferenciación del fenómeno de sus límites anteriores. El punto de partida de la segunda forma de intencionalidad parece ser un objeto metafísico, el cual merece la pena considerar como una inagotable fuente del mundo de los fenómenos.
\end{abstract}

Palabras clave: Fenomenología, metafísica, intencionalidad, creatividad humana.

Phenomenology and metaphysics - both seem to be mutually exclusive concepts. The first refers to the phenomena - things, events, ideas, desires, emotions, imaginary contents, works of art, poetry, literature - in short, all the contents of our internal and external life, all the forms of being, which are open 
toward the other forms of being and first of all, which are given to our consciousness.

Metaphysics appeals to the so called the "Thing in Itself" - the transcendent object, which has never been given to the consciousness. It is closed in itself and presents unknown object.

This traditional distinction between phenomenology and metaphysics seems not to comply with the modern philosophical thinking. The diversity of modern philosophy abounds with innumerable attempts to break the borders between these two main branches of philosophy.

The unknown concept of the "Thing in Itself" has no resistance against the critical philosophical peruse. Who can characterize the metaphysical object as an unknown thing if it is absolutely unknown? Since the very process of characterization has already brought to light the transcendent kingdom of an absolute darkness. Nevertheless, philosophers introduced this concept and moreover: they harbingered in handling this concept to resolve philosophical-cognitive problems.

One of the ways to explain this paradox is the following: while speaking about the metaphysical "Thing in Itself", the philosophers do not imply specifically the unknown and transcendent object. They have in mind the meaning of this object, which, as a significant content, is open to the consciousness. Thus, the meaning and the existence of the "Thing in Itself" differ from each other in principle; the first is open, whereas the second is closed to the consciousness. Hence, the meaning of the metaphysical object cannot reflect the existence of the same one. So, this way of explanation comes to the split between the meaning and existence of metaphysical object.

Our judgment seems to be scurrilous and maybe superficial point of view on the problem of metaphysics, mentioned above. More thorough and profound investigation leads us not only to the depth of more refine distinction, coming eventually to the integrity of meaning and being, but to the alteration of the style of thinking and to break of the stereotypical forms of judgment, we have been accustomed to.

The first obstacle we encounter here concerns the problem of being of the "Thing in Itself". How one could speak about the being of object if it was absolutely unknown? One could never assert whereas this object existed or not. One must take into account the "Thing in Itself" out of claim of being or not-being. 
Thus, one must take this object in brackets and that is the very phenomenological description of the metaphysical object.

Such weird and, moreover, self-contradictory issue of our metaphysical inquiry, (since we have encountered the incredible result for philosophical logics - the result of integrity of the metaphysics and phenomenology) is not certainly the synthesis of incongruous conceptions if we share the position of Edgar Allan Poe about the poetic principle ${ }^{1}$.

The great romantic writer came to the exactly phenomenological point of view of the poetic principle; a writer would be worth naming a certain poet if he had not been involved in an immediate experience of beauty and romantic life. He must have kept the distance between his desires, feelings, emotions, poetic ideas, stream of an artistic thoughts, wills, etc.

The distance shows that instead of a physical existence of beautiful things and psycho-emotional, romantic state of soul, a certain poet strives for the sublime, metaphysical beauty.

When an author or a reader of a poem bursts into tears it happens not because of the excessive emotions, but because of the sorrow that he is unable to attain the metaphysical beauty and cannot reach the sublime state of merging with the spiritual source of romantic feelings.

To put it differently, in the concepts of Bible, that is the sorrow for the Paradise, which is lost forever. Therefore, a poet's emotion is not purely aesthetical; it deals with the ethical principle as well. Striving for the metaphysics does not lead him to a poem for the sake of poem and to the beauty for the sake of beauty but it deals with moral sense of sinfulness because of the fall. Thus, the poetical strive for metaphysics does not attain the "Thing in Itself" (The beauty for the sake of beauty).

It turns into phenomenological way, which deals with the phenomenon of morality.

Unfolding this poetic principle in phenomenological manner, we can say that the poet undergoes not only the sorrow for unattainable beauty but he, at the same time strives for attaining this unattainable goal. He does not reject the beauty of physical things and internal reality of his psycho-emotional state. He

\footnotetext{
${ }^{1}$ Edgar Allan Poe. The Poetic Principle in; American Literary Criticism. Moscow, "Progress" 1981. pp. 59 $-68$
} 
uses these aesthetical points to construct the poem, but uses them conditionally, keeping the distance between his self and his emotions, since his intentionality has been directed to the metaphysical, unattainable beauty.

Here he comes across with the problem again: the distance between him and his work of art (since it has presented an issue of his romantic experience) inevitably reveals that he certainly deals with the metaphysical world and that his poem plays a role of a mediator between him and eternity.

On the other hand, if he had not been involved in the stream of creative emotions and thoughts, the poem would have become the dry skeleton of symbols, metaphors and ideas calling for revealing the unknown, metaphysical sphere.

If the structure of symbols and ideas was able to draw the curtain of the kingdom of metaphysical thing, the latter would lose its mystery and becomes the knowing thing. Consequently, instead of the "Thing in Itself", which is unknown in principle, we find the "Thing for the Consciousness" and the metaphysical world would be lost.

Therefore, the poet follows the vocation to keep the distance not only with the physical beauty, but also with the symbols leading him beyond physical reality to the kingdom of metaphysics.

Such double distance toward the opposite worlds is possible only in contradictory state of motion. The poet must be involved in physical and psychological experience of beauty (to make the distance and keep the inaccessibility of metaphysics) and at the same time, he must not be involved in the same experience of a physical beauty (to keep the strife for an inaccessible world).

Scrutinizing this position of this twofold distance, it becomes obvious that the poet comes to the phenomenological attitude. Keeping and not keeping the distance toward his poetical self (which bears the experience of the real, sensible beauty) the poet uses the phenomenological method; he takes this experience in brackets, keeps it conditionally as a phenomenon but not as a real state of his soul. He turns his romantic experience into a metaphor of the metaphysical beauty and plays a role of a person, who seems to be involved in this experience.

Generalizing this poetical principle into the principle of creativity of art, we come to the conclusion: 
It is an artistic reality of work of art, which makes the bridge between phenomenology and metaphysics.

The problem of relation of phenomenology and metaphysics is far to be exhausted either by the poetical principle, considered above or by the sphere of creativity of work of art in general.

We encounter here with a very difficult crux of the human thinking, which always slips away from the logical judgment.

As it was noted, the radical change of style of thinking seems to be unavoidable here. The crux of the matter is in fact that instead of constructing the process of thinking, we must deconstruct it.

The certain creativity, excludes the project, an a priori idea, preoccupation and foreseeing of the result of creativity. The work of art essentially arises in the space of freedom in the internal womb of creative action, without been enforced from outside, despite all the projects and ideas as attempts to anticipate and determine it in advance.

However, this ideal work of art dwells on a half way between phenomenology and metaphysics. If we were astute to come over this bridge and continue our way toward an unattainable and unknown object, we would keep our loyalty toward the principle of deconstruction of thinking at all. That means to reject not only any kind of project which would be given in advance, but also to withstand to any kind of mental construction which arises on its own in the freedom of creative action. That is certainly impossible state of thinking, since we are in permanent striving for deconstruction of any construction arising in our mind despite the fact, that the very process of deconstruction needs some constructive basis of resistance against any basis of construction. Yes, indeed it is unobtainable state of mind but we are urged to aspire this impossible state, to continue our way toward metaphysics.

There are two ways of helping us out from this state:

The first leads to intentionality of deconstructing and disintegrating all the constructions and eventually all the logical structure of thinking.

Such total deconstruction turns our language either into rambling of a madman, or into an utmost private, intimate and subjective speech, which would be deprived of communicative function and become absolutely incomprehensible. 
In his "myth of cave", Plato pointed out this metaphysical language, which sounded as a rambling of a madman.

In respect to this way, it would be worth noting that we could not follow this path, leading to the ultimate form of subjectivity. Otherwise, we would be in danger to be unknown and this paper could lose its scientific value.

The second way is specifically phenomenological.

On the way of creative activity, we are not in charge of deconstruction of mental contents arising in freedom of thinking. We can take them in brackets, or keep them conditionally, changing their meanings and abolishing their claims of being or not-being. That is the phenomenological way of deconstruction of the "giveness" of being to change it in the content of thinking: the way of shifting the sense from an existence to an essence.

Revealing the essence through the "giveness" of being, we attached the metaphysical sense to the phenomenon. The essence is worth considering to be an inexhaustible source of revealing phenomena. Hence, the essence is not the phenomenon. It realizes itself through the phenomena but since this realization has been interminable, the essence does not completely manifest itself as a phenomenon. Inasmuch an essence reveals itself as a phenomenon; it conceals itself as a metaphysical object. Here the way of self-revealing coincides with the way of self-concealing. On the one hand, we are unable to grasp the metaphysical object, since our consciousness has always dealt with the phenomena but on the other hand, we are responsible to take into account that the "openness" of phenomena derives from the metaphysical object, which is unobtainable and inexhaustible source of our thinking.

The second, phenomenological way, leading to the metaphysical object, has something in common with the first way leading to the same goal through the ultimate subjectivity of language. The thing is that although the metaphysical object is unknown, it influences and leaves a trail on our phenomenological world. This trail runs through the subjectivity of being.

Disintegration of logical structure of thinking and devaluation of communicative function of language both appear to be the tribute to keep the unknown status of metaphysical object.

Phenomenological shifting of sense of mental constructions, arising in creative freedom of thinking seems to be an attempt to grasp the trail of metaphysical object leaving it in our world of phenomena. 
What kind of trail we are speaking about?

This trail could not be the element of our cognition; otherwise, it would not correspond to the metaphysical object, which has never become the object of knowledge.

It would be an obscure and unconscious trail of influence of unknown "thing in itself", which has always striven against objectification of the knowledge and through the contingency and freedom it breaks the order of objective world.

In word, that is the subjectivity of being, which manifests itself in two spheres; in the sphere of consciousness, through the elusive self of psychoemotional phenomena and in the sphere of external world, through the freedom and irreducible probability of natural events.

Emergence of quantum theory in atomic physics and disclosing the irreducible probability and indeterminism of quantum events clearly confirmed these objective forms of subjectivity in the physical reality.

Quantum theory obviously shows that the matter as a phenomenon has an ability of self-interpretation and the essence should be considered beyond phenomena, as a metaphysical object.

The influence of this metaphysical essence introduces the subjective agent versus to objectivity of knowledge, against necessity and determinism of reality.

Therefore, to take into account the essence of phenomenon, above all we need to fix this subjective agent, which deconstruct the regularity of objective being.

The special phenomenological method is used to accomplish this task - the method of bracketing the phenomenon that means to wrest it from the determinism of objective being.

Unfolding this position, finally we could come to the point that, it would be the influence of the metaphysical world that create obstacles to insight completely the self of subject and to cognize the world in the absolute light of logical accuracy.

Therefore, the elusiveness of the self and the error of human cognition, both have positive values, since they have indicated the influence of metaphysics on the phenomenological world. 
Looking back through our work, the feeling of dissatisfaction accompanies us, since instead of deconstruction of the mental forms which leads certainly to the unknown object we use ready-made phenomenological conception to bridge the gap over phenomenology and metaphysics.

Therefore, the subtle way of creativity between certainty and uncertainty of thinking slipped away.

We encounter here again and again with impossibility to express our object. The process of the expression like a river of Heraclitus thrill me away in a depth of unconscious where any mental constructions, arising in this dizzy dance of the thoughts and the words must be overcome and destroyed. On the other hand I am aware that it is the contradictory way of thinking since my stream of thoughts presents the striving for an aim which makes an intentionality of thought and brinks to light the darkness of this unconscious state. It is certainly impossible state of mind since I aspire to a full freedom taking into account that the freedom always slips away, since my creative thought is intentional; it is motivated by an aim and besides, I use the readymade words and concepts. They are given to me in advance as a form of my knowledge which enslaves me.

I am on the verge of despair and happiness. I am in despair since I am aware that I can not swim the ocean of freedom without the boat which is constructed by the language, otherwise I would be under the sword of Damocles to sink in a senseless speech of a madman.

I am happy because despite this danger I feel the strong desire to leave the boat and swim and follow the hidden stream of an ocean to find something new as a result of my risk to be perished.

Striving for an unknown I am not motivated by an aim. I am even ignorant does this aim exist or not. The driving wheel of my venture is the desire to leave the boat, to break the limits which imprisoned me. I have an intentionality (without intentionality my motion would lose the sense and coincides with madness) but it is not an intentionality for an aim. It is an intentionality to leave the boat, to break the limits and swim for the freedom.

One significant remark: my desire to leave the boat is not rational; it is not motivated and purposeful process. It rather belongs to the sphere of passions. I perceive the boat as a prison and I have a strong desire as a feeling of aspira- 
tion to get rid of myself. I keep my striving for the freedom on the level of passion not to turn it into the rational, purposeful process which would destroy it. To maintain the freedom and creative function of my desire I must retain it in the sphere of unconscious passion.

In respect to this problem it would be worth citing the work of professor Tymieniecka A-T:

Indeed, in its progress the creative function is a mechanism of discrimination, deliberation, and selection. But so is the passive genesis. However, in opposition to the latter, which works with the material of rational elements of structurizing and their selective principles, the mechanism of choice of the creative function is constantly oriented and reoriented in its modalities by fluctuating inclinations, tendencies, expectations, aspirations, hidden longings, aversions, and sympathies; all of them, whether they are dispositional or acquired within the present world (being matters of feeling, taste, belief, etc.) seem to escape the authority of our rational powers. $^{2}$

Our analyses eventually come to the point that the phenomenological intentionality as an acts of creativity and liberation does not coincide with purposefulness. Two kinds of intentionality appear to display the freedom going beyond the purpose. "Intentionality - to" and "Intentionality -from". The first presents the orientation of consciousness to structure the phenomena and construct the object of perception, according to an aim. It coincides with purposefulness. The second form of intentionality, "intentionality - from", presents the unconscious striving for freedom against objectification of knowledge. It expresses the creativity and openness of consciousness toward the metaphysical object which has never released in the world of phenomena.

These two forms of intentionality merges with each other and there is no way to distinguish the one from an other. Nevertheless they have different meanings and act in a different ways. At the very beginning of act of creativity there is a phenomenological mood to go beyond borders in a depth of unknown sphere. This unconscious state is supported by the inner working of consciousness which refers to the "intentionality-from". Otherwise, the striving for the freedom leading to the deconstruction of language would fall in anarchy and

\footnotetext{
${ }^{2}$ A-T Tymieniecka . Roman Ingarden's Philosophical Legacy and My Departure from It: The Creative Freedom of the Possible Worlds. In; Analecta Husserliana, vol XXX p. 18
} 
chaos of madness. To avoid this danger, phenomenological mood, as an incipient point of creativity implies the consciousness as a second form of intentionality.

As soon as consciousness, in the freedom of creativity distinguishes itself from the being, it would be generated as an "intentionality - from". At the same time, it constitutes and mirrors the being and turns itself into the "intentionality - to". The new phenomenon of the human world presents an integral result of collaboration of these two forms of intentionality.

Thanks to "intentionality-from", this phenomenon presents the unique fruit of creativity and differs in principal from the previous phenomena. Because of "intentionality- to", it reflects the suppressed being and dealing with general essence follows the dynamic order of the human world.

Here we encounter again with strong impact of metaphysical object, which seems to maintain its unknowable nature in the process of human creativity. This influence consists in fact that creative function of "intentionalityfrom" reveals the insurmountable distance between consciousness and its object, which as a transcendent object, plays a role of metaphysical thing.

Although the latter is incomprehensible, it is not closed for the consciousness and manifests itself through the freedom of creativity and subjective tendencies of phenomenological mood.

We introduce the "intentionality - from" to avoid the chaos in deconstruction of any mental constructions arising in our searching for the metaphysical thing. Thus we confer the status of creativity on the process of deconstruction of thinking turning it into an act of disclosing the thought toward the metaphysics.

"Intentionality-from" has a creative function to distinguish itself from the being, to break the previous giveness and to go beyond any kind of borders. It seems to escape the authority of rational powers and dwells in subjectivity of phenomenological mood.

"Intentionality - to" is connected with constitutive activity of consciousness. It uses the phenomenological method (epoche) to reveal the essence of being and brink to light the act of cognition.

Although we separate these two forms of intentionality, really they are conjoined and overlap themselves. Indeed! It is really incredible to inspect the 
separate trails leading in opposite forms of intentionality. Rather we perceive them integrally dealing with positive evaluation of negative acts.

If we interpreted the act of deconstruction in positive sense considering it as an act of differentiation for sake the freedom we would come to the constitutive activity of consciousness - with "intentionality-to". Therefore the process of deconstruction of thinking in its metaphysical openness means the act of creation of object and "intentionality-from" immediately turns into "intentionality-to". Therefore as soon as I feel the freedom from the giveness of being I become aware that it is my striving for breaking the old form and creating the new one. Although my feeling is actual, I can not retain the freedom really it would be transformed in imaginary phenomenon. . But this imaginary freedom is not the groundless fantasy it is really founded on the conjoined forms of intentionality, mentioned above.

Coexistence of this opposite forms makes the balance between tension of purposeful striving and relaxation in freedom. Intentionality as a result of coercing forms goes beyond any specific purpose; it spreads endlessly embracing all the mental activities and reveals the essential structure of consciousness. As a matter of fact, thanks to this essential and everlasting intentionality, the consciousness refers to an inaccessible object and is open toward the transcendent sphere. The object of metaphysics - the interminable goal of this openness stands beyond any concrete achievements of thinking providing the latter with creative freedom.

Our tendency to deconstruct any mental construction arising in the searching for metaphysical thing expresses the unlimited nature of intentionality which would be impossible if we dealt with only "intentionality - to". Leaving the boat of language for swimming the ocean of freedom we refer to the "intentionality- from" which helps us out of senseless speech of madman. It keeps the language conditionally, taking it in brackets, in status of ideal "phenomenon in itself" which would not be determined by an external being. Eventually, we will find ourselves in a dreamy vortex of playful words, metaphors, illusions, hidden desires, unwilling thoughts, game of fantasy. All this stream of consciousness seems to have no basis underneath but here, thanks to the "intentionality-to" the diversity of this creative phenomena gains the sense of striving for an inaccessible, sublime beauty which plays a role of metaphysical object. 
The painful sensation of distance between the creative self and sublime object has positive sense since it keeps the work of art (including any achievement of creative thought) in state of openness toward the unconscious. Despite the final point, the achievement of creativity must be considered as incomplete in principal. It would be open in perspective of further development to keep certain creativity leading to the mystery of the metaphysical world.

Now to stipulate our special standpoint concerning the metaphysical thing we would like to address to the work of Professor Jiro Watanabe - Heidegger's Phenomenology of Being and Husserl's Phenomenology of Consciousness ${ }^{3}$. The author analyses Husserl's idea that

being is not in the object, is no part of it, no moment dwelling in it. Neither is it attaching to an object...Being is no real predicate... Being is absolutely imperceptible... Being is no sensuously perceptible but supersensuously self-given... in the higher perception of the state of affairs... namely in the categorial intuition.

Sharing this position we dare assume some remark. The being seems not to be the real predicate. I can perceive the color, the form, the smoothness of thing but can not perceive the states of being -colored, being-smooth; I can hear the sound but can not hear the something which is sounding. There is no doubt that the being is not the predicate, it is the subject and all the diversity of perceptible phenomena is attached to this subject. Consciousness as an "intentionality-to" perceives or creates this phenomena and brings them into correlation with subject that is the being.

Here the question arises; would it possible to attach the predicate to the subject if there was no similarity between them? One should admit some common, united point between predicate and subject otherwise this logical link would be destroyed. Such kind of similarity means that the subject is not absolutely strange for predicate and there would be the cognitive situation when the

\footnotetext{
3 Jiro Watanabe. - Heideger's Phenomenology of Being and Husserl's Phenomenology of Consciousness. In: Phenomenology World-Wide. - Encyclopedia of Learning. Kluwer Academic Publishers. 2002. p 243
} 
subject becomes the predicate and vise-versa. Hence in the context of our judgment we must assume the situation when the being turns into the predicate and transforms itself in a perceptible thing. But it is not the real situation. Reality is exhausted by the phenomena and besides, the language of actual world is unable to determine the being as a predicate (like the form, color, smoothness, sound, taste... etc.). Hence the situation when the being is perceptible exists beyond the language and out of sphere of objective reality; it belongs to the area of possible worlds. When the consciousness constitutes the world of phenomena in which we live, it at the same time have in mind the possibility of being as a perceptible thing although the latter has never been perceived really. That is our understanding of Husserl's instruction that the act of phenomenological constitution also takes into account the being as a basis of this constitution. It is possibly perceptible although this possibility always slips away from the reality.

If the being as a possibly perceptible thing presented itself beyond the world of phenomena it would coincide with metaphysical object and it needs the special ability of consciousness to be perceived. "Intentionality-to' is unable to accomplish this task since it operates with diversity of phenomena. It is my conviction to say that here we needs the second form of consciousness, the "intentionality-from" which goes beyond the purposefulness and is open toward the metaphysical sphere. As it refers to the sphere of possibilities which have never realized actually, "intentionality-from" uses imagination to keep the metaphysical status of being and to turn it into perceptible thing. Imagination here presents the basis of perception and it appeals to the creative function of mind.

Our analyses eventually comes to the point that, metaphysical object is not absolutely closed "thing in itself". It is open toward the consciousness. It has never entered the field of

Consciousness but at the same time it is always taken into account as a possibly perceptible thing. Therefore it plays the role of basis which transforms the constituted phenomena in the real world of perceptible objects. "Openness" presents the most pertinent name, reflecting this nature of metaphysical being. "Openness" of being presents the inexhaustible source of phenomenological constitution and on the other hand, as a pure possibility, it always stays beyond constituted phenomena keeping the mystery of metaphysical world. 
The more the "Openness" of being reveals itself as a phenomenon, the more it conceals itself as a metaphysical thing.

Beyond the world of phenomena there is a metaphysical being in mode of "Openness in itself" which presents the self-existing being which is possibly opened toward the consciousness; although the latter has never realized in actual status of "intentionality-to". That means that consciousness does not exist and the being, as a metaphysical thing is open toward itself. But at the same time it must be open toward the consciousness to provide the world of phenomena with status of being. Hence the being as a metaphysical thing includes in itself the consciousness as a not-being. Consciousness in mode of "intentionality - from" differs from being and at the same time dwells within the metaphysical being as a not-being.

Non -existence of consciousness turns it into the mirror, which reflects the being. If this mirror had its own being it would need the other consciousness to reflect this being and so on endlessly...Therefore the being which roots in metaphysics and at the same time presents the basis of phenomenological world includes in itself the not-being as a mirror and presents the self-reflecting being. As a metaphysical object it exists independently, beyond the consciousness but on the other hand it implies the consciousness as a not-being within its being.

Therefore emergence of human consciousness would be unavoidable stage of creative development of the phenomenological world if it rooted in metaphysical being. Perfect state of being is impossible without the point of selfreflection which leads it beyond itself to the consciousness. Two forms of consciousness - "intentionality-from" and "Intentionality-to" regulate this selfexisting process and makes the correlation between metaphysical object and phenomenological world. 